\title{
Heat Stability of Differently Stabilized Solid Lipid Nanoparticles in the Presence of Excess Bulk Phase Protein
}

\author{
Verena Wiedenmann $^{1,2}$ (I) $\cdot$ Kathleen Oehlke ${ }^{1} \cdot$ Ulrike van der Schaaf $^{2} \cdot$ Katrin Schrader $^{3} \cdot$ Heike Petra Karbstein $^{2}$
}

Received: 8 February 2019 / Accepted: 17 May 2019 /Published online: 6 June 2019

(C) The Author(s) 2019

\begin{abstract}
In order to apply emulsion-based delivery systems to food, they have to be stable in a protein rich environment. This study investigated the stability of solid lipid nanoparticles (SLN) during heat treatment in the presence or absence of $\beta$-lactoglobulin (BLG). SLN were stabilized either by Tween 20 (TS) or by the protein itself (BS) and were enriched to a total BLG content of $56 \mathrm{mg} / \mathrm{mL}$. The sizes of both types of SLN were initially in the range of $170 \mathrm{~nm}$. The amount of free protein was determined before and after enrichment with BLG. As revealed by particle size and zeta potential measurements, a protein layer of BLG (hard corona) adsorbed on BS but not on TS. By contrast, a soft corona was formed around both BS and TS. SLN were heat treated in the presence and absence of protein and were characterized regarding size and zeta potential. According to transmission electron microscopy imaging, heating did not affect the shape of TS and BS: TS were platelets, whereas BS exhibited a spherical or platelet like shape. Upon heat treatment, the particle size of TS increased to about 3.5 fold of the initial size (to appr. $600 \mathrm{~nm}$ ) in the presence and in the absence of excess protein. The cloudy protein layer (soft corona) around TS could thus not prevent coalescence of TS. By contrast, BS did not experience a change in particle size. Hence, by the choice of emulsifier, an encapsulation system that is stable against heat treatment can be obtained.
\end{abstract}

Keywords Heat treatment $\cdot$ Whey proteins $\cdot$ Coalescence $\cdot$ Corona $\cdot$ Tween $20 \cdot \beta$-Lactoglobulin

\section{Introduction}

Delivery systems like microgel particles, (nano-) emulsions, liposomes or solid lipid nanoparticles (SLN) gained increasing interest to enrich food systems with bioactive compounds, antioxidants, preservatives or flavors [1-3]. SLN have great

Electronic supplementary material The online version of this article (https://doi.org/10.1007/s11483-019-09588-w) contains supplementary material, which is available to authorized users.

Verena Wiedenmann

verena.wiedenmann@mri.bund.de

1 Federal Research Institute of Nutrition and Food, Department of Food Technology and Bioprocess Engineering, Max Rubner-Institut, Haid-und-Neu Str. 9, 76131 Karlsruhe, Germany

2 Institute of Process Engineering in Life Sciences, Chair for Food Process Engineering, Karlsruhe Institute of Technology, Kaiserstr. 12, Karlsruhe, Germany

3 Federal Research Institute of Nutrition and Food, Department of Safety and Quality of Milk and Fish Products, Max Rubner-Institut, Hermann-Weigmann-Straße 1, 24103 Kiel, Germany potential to encapsulate substances or to modify food structures like gels $[2,4]$. They are colloidal lipidic systems and can be regarded as crystallized O/W-nano-emulsions. SLN can be stabilized by low molecular weight emulsifiers like Tween 20 and / or proteins. For a possible application in food systems, SLN need to be stable against stress and environmental changes as they are expected to maintain their functionality as encapsulants during processing, storage and consumption. In our previous study, protein-stabilized SLN were stable during heat treatment in the presence of $\beta$-lactoglobulin (BLG), whereas Tween 20-stabilized SLN coalesced under similar conditions [4]. The aim of the present study was to investigate this phenomenon in more detail. However, heating is a process step, that is often used to enhance shelf live or to control the viscosity of the product. It has been shown that heating above the denaturation temperature of whey proteins may lead to instabilities and break down of emulsions as globular proteins unfold and aggregate due to denaturation $[5,6]$. The amount of free protein has a major impact on the flocculation of whey protein stabilized emulsions: With increasing amount of whey protein concentrate (WPC, from 5 to $20 \mathrm{mg} / \mathrm{mL}$ ), the aggregation rate of droplets increased [6]. Similar results were reported by 
Sliwinski et al. 2003, who found increased droplet sizes after an increase of whey protein isolate (WPI) concentration from 15 to $30 \mathrm{mg} / \mathrm{mL}$ [5]. On the other hand, Kim and coworkers found an increased emulsion stability as they increased the protein concentration from $4 \mathrm{mg} / \mathrm{mL}$ to $10 \mathrm{mg} / \mathrm{mL}$ [7].

It is well known that proteins adsorb on surfaces and can consequently change the stability and surface chemistry of macro, micro or nanometer-sized particles [8-11]. A detailed description of the protein adsorption on nanoparticles (NP) and their different interactions between NP and cells was given by Dawson and colleagues [12]. Here, the term 'Protein Corona' was first mentioned. The formation of a protein corona depends on many factors, which include the charge, size and colloidal stability of NP [13-16]. Furthermore, the type of protein as well as temperature, incubation condition and time has an influence on corona formation [17-21]. Milani et al. showed that a corona comprised different protein layers [22]. The first layer is irreversibly adsorbed to the surface ("hard corona"), whereas the outer layers are bound more weakly ("soft corona"). These weakly bound proteins interact with the proteins of the hard corona and can be easily exchanged or washed-off.

Göppert and Müller discovered the adsorption of low amounts of human serum proteins onto SLN that were stabilized by different polysorbates or polyxamers [17, 18]. As a lot of studies on NP corona formation have been carried out under pharmaceutical aspects, most of them were conducted with human plasma protein. Yet, there are some studies that investigated the corona formation of dairy proteins: Winuprasith et al. and Yang et al. investigated the adsorption of $\beta$-lactoglobulin onto gold nanoparticles and Oehlke and colleagues could show that BLG formed a soft corona around edible SLN [23, 24, 25].

The aim of the present study was to investigate how protein layers affect the heat stability of SLN. Therefore, SLN were characterized before and after heating in the presence and absence of protein. The experiments were set up in a way that allowed distinguishing between effects caused by a hard or soft corona. Therefore, Tween 20-stabilized SLN (TS) were studied in the absence of protein and in the presence of protein in the continuous phase, where only the formation of a soft corona was expected according to our earlier study [25]. BLG-stabilized SLN (BS) were expected to inherently contain a hard corona. In the presence of excess bulk phase protein, the formation of an additional soft corona seemed possible. Samples were characterized before and after heating regarding the amount of adsorbed protein, zeta potential, microstructure and size.

\section{Materials and Methods}

\section{Materials}

BiPro whey protein isolate was kindly donated by Agropur Ingredients (Eden Prairie, MN, USA). Glyceryl tristearate and
Tween 20® (Polyoxyethylene sorbitan monolaurate, Tween 20) was purchased from Sigma Aldrich (St. Louis, Missouri, USA), sucrose palmitate from Alfa Aesar (Karlsruhe, Germany). Soy lecithin "Emulpur IP" was kindly donated by Cargill (Cargill Texturizing Solutions, Hamburg, Germany). Potassium-di-hydrogen phosphate was purchased from Carl Roth GmbH (Karlsruhe, Germany), hydrochloric acid, sodium hydroxide and di-sodium hydrogen phosphate from Merck KGaA (Darmstadt, Germany). All solutions were prepared in demineralized water.

\section{Purification of $\beta$-Lactoglobulin}

BLG was isolated from whey protein isolate (WPI), following a method described by Keppler et al. [26] with slight modifications: $20 \%(w / w)$ WPI was dissolved in demineralized water and hydrated for $18 \mathrm{~h}$ at $8^{\circ} \mathrm{C}$. Subsequently, the $\mathrm{pH}$-value was adjusted to 4.8 with hydrochloric acid to precipitate remaining caseins. Caseins were separated by centrifugation at $3220 \mathrm{~g}$ for $20 \mathrm{~min}$. The $\mathrm{pH}$-value of the remaining protein solution was now set to 3.8 with hydrochloric acid and heated to $55^{\circ} \mathrm{C}$ for $30 \mathrm{~min}$. During this heat treatment, all whey proteins except BLG were precipitated and removed by centrifugation at $20^{\circ} \mathrm{C}$ at $3220 \mathrm{~g}$ for $20 \mathrm{~min}$. The $\mathrm{pH}$-value of the remaining supernatant was readjusted to 7.0 with sodium hydroxide before washing the protein three times with ultrapure water by ultrafiltration (Amicon Ultra-15, PLGC Ultracel-PL Membran MWCO of 10 kDa, Merck KGaA, Darmstadt, Germany). BLG solution was collected and freeze dried.

To determine the purity and denaturation degree of BLG, reversed phase-high performance liquid chromatography (Agilent 1290 Infinity LC System HPLC) was applied with a fluorescence detector and $\mathrm{C}-18$ reversed-phase column (AerisTM XB-C18 Wide Pore $3.6 \mu \mathrm{m}, 200 \AA$ LC Column $50 \times 2.1 \mathrm{~mm}$, Phenomenex, Torrance, United States).

The denaturation degree of BLG was determined using the respective German Industrial Standard procedure (DIN 10473, German Industrial Standard, 1997). Samples were analyzed before and after a pH-adjustment to 4.6 with hydrochloric acid. At this $\mathrm{pH}$, denatured BLG will precipitate and was removed by filtration (syringe filter, $0.2 \mu \mathrm{m}$, Merck KGaA, Darmstadt, Germany). The concentrations of the supernatants were determined using the following procedure: The injection volume was set to $10 \mu \mathrm{L}$ at a flow rate of $1.2 \mathrm{~mL} \cdot \mathrm{min}^{-1}$ and a column temperature of $40{ }^{\circ} \mathrm{C}$. Eluents A $(0.1 \%(v / v)$ trifluoroacetic acid (TFA) in water) and B $(0.1 \%$ TFA $(\mathrm{v} / \mathrm{v})$ in acetonitrile) were used. Used elution gradient steps were $35-42.5 \% \mathrm{~B}$ (1-12.5 min), 42.5-46\% $\mathrm{B}(12.5-20.5 \mathrm{~min}), 46-35 \% \mathrm{~B}$ (20.5-22 $\mathrm{min})$, and $35 \% \mathrm{~B}$ (22-23 min). Fluorescence was monitored at excitation and emission wavelengths of 225 and $340 \mathrm{~nm}$, respectively. The degree of denaturation corresponded to the relative 
difference of the BLG concentration before and after precipitation and was below $1 \%$.

\section{Solid Lipid Nanoparticle Preparation}

SLN were prepared by ultrasound assisted hot emulsification as described by Oehlke et al. [2]. In short, $2.5 \mathrm{~g}$ of tristearin with $0.125 \mathrm{~g}$ lecithin was heated to $80^{\circ} \mathrm{C}$ for at least $30 \mathrm{~min}$ to remove any crystal memory. $22.375 \mathrm{~g}$ of $3.02 \%(w / w)$ sucrose palmitate in $5 \mathrm{mM}$ phosphate buffer was added at $80^{\circ} \mathrm{C}$ and immediately transferred to emulsification: We applied a sonicator (Sonoplus HD 3100, Bandelin electronic GmbH, Berlin, Germany) with a titanium tip (VS70T) at amplitude of $75 \%$ in pulsed mode $(0.5 \mathrm{~s}$ on/off $)$ at $80^{\circ} \mathrm{C}$.

In order to prepare Tween 20 stabilized SLN (TS), the hot emulsion was mixed with a hot $\left(80^{\circ} \mathrm{C}\right) 8 \%(w / w)$ Tween 20 solution in equal amounts and immediately cooled to $20^{\circ} \mathrm{C}$ in ice water under stirring.

Protein stabilized SLN (BS) were prepared by mixing one part emulsion at $60^{\circ} \mathrm{C}$ and one part of a cold $10 \mathrm{mg} / \mathrm{mL}$ BLG solution. The resulting emulsion was immediately cooled to $20^{\circ} \mathrm{C}$ in ice water under stirring.

The prepared SLN were subsequently centrifuged at $3220 \mathrm{~g}$ for $10 \mathrm{~min}$ to remove any titanium that was abraded during the sonication.

\section{Determination of SLN Size and Zeta Potential}

Particle size and zeta potential were analyzed applying a ZetaSizer Nano ZS (Malvern Instruments, UK). Zeta potentials were measured via electrophoretic mobility. Prior to the measurements, the sample conductivity was set to $50 \mu \mathrm{S} / \mathrm{cm}$ by diluting with ultrapure water. The particle size of the samples was determined by dynamic light scattering with a backscatter angle of $173^{\circ}$. Protein-enriched unheated SLN were diluted with two different solvents prior to particle size analysis: SLN samples were diluted 1:50 by either $5 \mathrm{mM}$ phosphate buffer or protein solution to maintain the protein concentration of $56 \mathrm{mg} / \mathrm{mL}$. SLN-samples that were heated or not enriched in protein were diluted with ultrapure water. The zaverages were analyzed based on the intensity based particle size distributions using Mie theory. All measurements were performed at $25^{\circ} \mathrm{C}$.

\section{Determination of Free Protein and Washing of Protein Stabilized SLN}

The non-adsorbed protein was removed from BS by ultrafiltration (Amicon Ultra-2, Millipore Ultracel Membrane, regenerated Cellulose, MWCO of $100 \mathrm{kDa}$, Merck KGaA, Darmstadt, Germany). $1.5 \mathrm{~mL}$ of BS suspension was centrifuged for $5 \mathrm{~min}$ at $3220 \mathrm{~g}$. Subsequently, the filtrate was stored for analysis and the supernatant was mixed with an equal amount of buffer and subsequently centrifuged for $20 \mathrm{~min}$ at $3220 \mathrm{~g}$. After centrifugation, the filtrate was again collected and the supernatant refilled with buffer. This procedure was repeated for eight times to remove the non-adsorbed protein. All filtrates were stored and analyzed regarding their protein concentration via photometry at an absorption wave length of $279 \mathrm{~nm}$. The supernatants were collected for further analysis: an aliquot was analyzed regarding particle size and zeta potential as described above. The rest was heat treated as described in section Heat Treatment of SLN.

\section{Determination of Free Protein and Size of Protein Enriched SLN}

SLN were mixed with BLG to achieve a total protein content of $56 \mathrm{mg} / \mathrm{mL}$ and left to hydrate for $18 \mathrm{~h}$ at $8^{\circ} \mathrm{C} .1 \mathrm{~mL}$ of each sample was ultrafiltrated using Sartorius Vivaspin-2 with a membrane of polyethersulfone and MWCO of $300 \mathrm{kDa}$ (Sartorius, Göttingen, Germany). The samples were centrifuged at $2000 \mathrm{~g}$ until $100 \mu \mathrm{L}$ filtrate were obtained. BLG concentrations of the filtrates were analyzed using photometry as described above. Preliminary tests with the ultrafiltration devices showed a protein recovery of approximately $98 \%$ after one filtration step.

\section{Heat Treatment of SLN}

TS and BS were heated for $30 \mathrm{~min}$ at $90^{\circ} \mathrm{C}$ under stirring and subsequently cooled in ice water to approximately $20^{\circ} \mathrm{C}$. An aliquot was stored for analysis, the remaining was again heat treated. This was repeated for 5 times. The collected aliquots were analyzed regarding their particle size and zeta potential as described above.

Protein enriched SLN were heat treated in the same manner, but only one time for $30 \mathrm{~min}$. Suspensions were diluted with buffer and analyzed by DLS regarding their size and zeta potential.

\section{Transmission Electron Microscopy (TEM)}

Selected SLN samples were examined by transmission electron microscopy (TEM) using the freeze fracture technique as described here [27]. For cryoprotection, the samples were mixed with $30 \%$ glycerol. Small droplets were cryofixed by immersion into melting Freon $22\left(-160{ }^{\circ} \mathrm{C}\right)$. Specimens were freeze-fractured at $-120{ }^{\circ} \mathrm{C}$ and immediately replicated by $\mathrm{Pt} / \mathrm{C}$ and $\mathrm{C}$ electron gun evaporation using a BAL-TEC BAF 400 unit (Balzers, Liechtenstein). The replicas were cleaned in concentrated sodium hypochlorite and in acetone with repeated rinses in distilled water. Afterwards they were examined and photographed with a FEI Technai 10 (Eindhoven, the Netherlands) transmission electron microscope operated at $80 \mathrm{kV}$. 


\section{Statistical Analysis}

All tests were performed at least three times if not stated otherwise. Results are presented as calculated means with standard deviations. Results were considered statistically significant with $p<0.05$ after t-test or Mann-Whitney rank sum test if normality or equal variance was not given, applying SigmaPlot 13.0 (Systat Software GmbH, Erkrath, Germany).

\section{Results}

\section{Properties of Unheated SLN}

To study the structure and properties of SLN before heating, the size, zeta potential, and shape of two kinds of SLN were determined: SLN were either stabilized by Tween 20 (TS) or by BLG (BS). Additionally, the amount of adsorbed protein on BS was determined.

TS had a size of $173 \pm 4 \mathrm{~nm}$ and exhibited a zeta potential of about $-33 \mathrm{mV}$. BS were comparable in size and had a zeta potential of approximately $-49 \mathrm{mV}$ (Table 1 ). The polydispersity index of TS and BS was below 0.3 , indicating a relatively narrow size distribution. These values are in accordance with earlier work [4]. The more negative surface charge of BS was probably due to adsorbed protein which is known to have a negative charge at $\mathrm{pH} 7$ [28].

TS exhibited a platelet-like shape, whereas both spherically and platelet shaped BS were detected (Fig. 1). The shape and size of SLN can vary due to different stabilization mechanisms and polymorphism: $\beta$ '-polymorph particles are known to form needle- or disc-like shapes. In contrast, $\alpha$ modifications led to more spherical shaped crystals [29]. However, no further tests on the morphology of the crystals were done as this was not the main aspect of this study.

In order to ensure that BS were stabilized by BLG, BS were washed and the amount of free protein and washed off protein was analyzed. Prior to any washing steps, approximately 0.88 $\mathrm{mg} / \mathrm{mL}$ BLG was freely present in the continuous phase (Figure 2). $5 \mathrm{mg} / \mathrm{mL}$ BLG were used to stabilize BS during preparation.Consequently, about $4.1 \mathrm{mg} / \mathrm{mL}$ were adsorbed onto the particles' surface at a total protein concentration of $5 \mathrm{mg} /$ $\mathrm{mL}$. After eight washing steps, the total protein content in the suspension dropped to $3.3 \pm 0.1 \mathrm{mg} / \mathrm{mL}$ protein, of which 98.0

Table 1 Size (z-average), polydispersity index (PDI) and zeta potential of two kinds of SLN: BS were stabilized by BLG whereas TS were stabilized by Tween 20

\begin{tabular}{llll}
\hline & z-average & PDI & Zeta potential \\
\hline TS & $173 \pm 4 \mathrm{~nm}$ & $0.273 \pm 0.005$ & $-32.7 \pm 1.4 \mathrm{mV}$ \\
BS & $169 \pm 3 \mathrm{~nm}$ & $0.188 \pm 0.016$ & $-48.9 \pm 1.6 \mathrm{mV}$ \\
\hline
\end{tabular}

$\pm 0.2 \%$ was adsorbed. I.e. $3.2 \pm 0.1 \mathrm{mg} / \mathrm{mL}$ BLG was attached to the particles' surface. As the amount of free protein did not change with further dilution and washing, we conclude that this amount of protein was firmly adsorbed to the surface of the SLN, whereas the remaining protein was free in the solution. The zeta potential of washed BS was similar to unwashed BS, which indicated that the protein was indeed still adsorbed on the surface and the particles were fully covered. Details of the zeta potential results are given in the supplement.

\section{Properties of SLN in the Presence of Excess BLG}

A possible formation of an adsorption layer on both kinds of SLN was studied. Therefore, we determined the free and adsorbed protein on SLN by ultrafiltration, the size of the particles in the presence of high protein contents as well as their zeta potential.

The zeta potential of freshly prepared BS was about $-49 \mathrm{mV}$ and remained unchanged after the addition of further BLG to the BS suspension (Fig. 3 and Table 1). This indicated that the surface of BS was already fully covered and a further addition of BLG did not change the adsorption layer of the protein. TS had a zeta potential of approximately $-30 \mathrm{mV}$ and was not affected by the addition of $56 \mathrm{mg} / \mathrm{mL}$ BLG, as well (Fig. 3 and Table 1). Tween 20 is known to reduce interactions between particle surfaces and proteins [30]. Hence, it is likely that BLG did not adsorb to the surface of TS, so that the zeta potential was not affected by the enrichment with protein.

To determine a possible formation of a corona around the particles, the size of SLN was analyzed before and after the addition of BLG. Figure 4 presents the particle size distributions of SLN directly after preparation and the size distributions after protein enrichment to $56 \mathrm{mg} / \mathrm{mL}$. Prior to the size measurements, the particle suspensions had to be diluted to achieve good measurement conditions. Samples were diluted either with BLG solution maintaining a protein concentration of $56 \mathrm{mg} / \mathrm{mL}$ or with buffer solution.

In the absence of excess protein, both kinds of SLN exhibited a monomodal size distribution. After the addition of BLG, SLN were still stable and did not show visible phase separation or flocculation. Neither TS nor BS showed altered size distributions after enrichment with BLG and dilution with buffer solution (Fig. 4). Upon dilution with buffer, the protein concentration dropped to approximately $1.1 \mathrm{mg} / \mathrm{mL}$. This was expected to change the balance between the free and adsorbed protein, leading to the desorption of only weakly attached protein. I.e. the soft corona would be washed off and only a hard corona was supposed to be maintained [22]. The unchanged particle size distribution of TS reflected that no protein was tightly adsorbed to the particle surface. This was supported by the zeta potential, as discussed above. I.e. no hard corona was formed around TS. In BS suspensions, on the other hand, BLG was already present during the 
Fig. 1 Freeze-fracture TEMimages of untreated SLN: A) SLN that were stabilized by Tween 20 (TS), B) SLN that were stabilized by BLG (BS). Both images have the same magnification represented by the bar in the left image
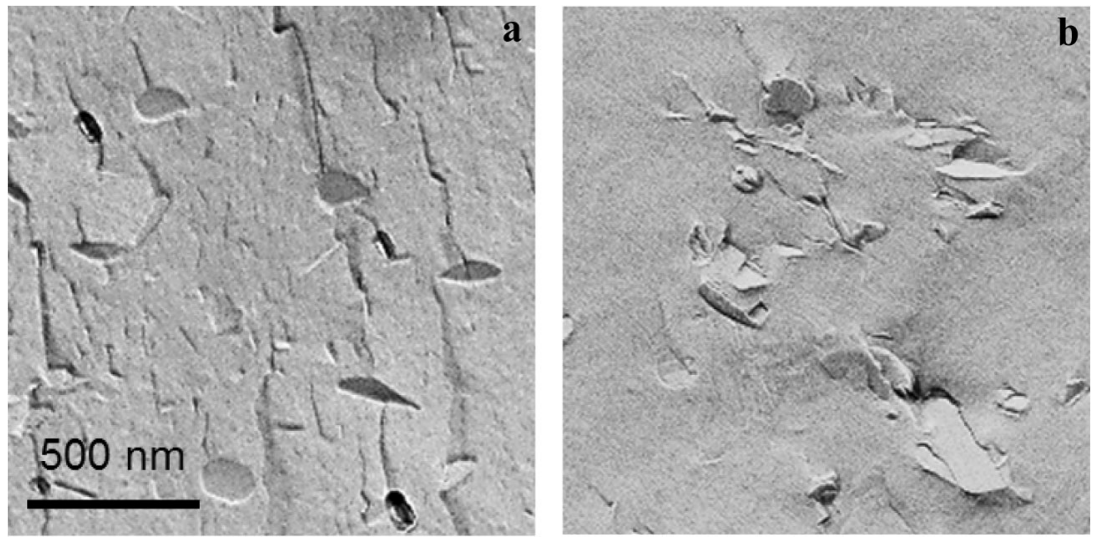

preparation of BS and stabilized the particles. The particle size of freshly prepared BS hence already included the protein layer at the particle surface. A further increase in size after protein enrichment and subsequent dilution with buffer was hence unlikely and did not occur (Fig. 4).

To assess if a soft corona had formed, SLN suspensions were diluted by a protein solution to maintain a protein concentration of $56 \mathrm{mg} / \mathrm{mL}$. Consequently, we assumed that the equilibrium between non-adsorbed and adsorbed protein would not change, and a loosely attached protein layer would increase the size of SLN. Particle size distributions of both BS and TS shifted to bigger sizes after their enrichment with BLG and subsequent dilution with protein solution, indicating the formation of a protein layer around the particles (Fig. 4). To investigate this layer formation by a second method, the free protein in the enriched dispersion was determined to calculate the amount of protein that possibly formed a soft corona around SLN. In ultrafiltration experiments, TS retained 38.2 $\pm 1.0 \mathrm{mg} / \mathrm{mL}$ protein, whereas BS retained $32.2 \pm 0.4 \mathrm{mg} / \mathrm{mL}$ (Fig. 5). In a soft corona, protein is loosely attached to the

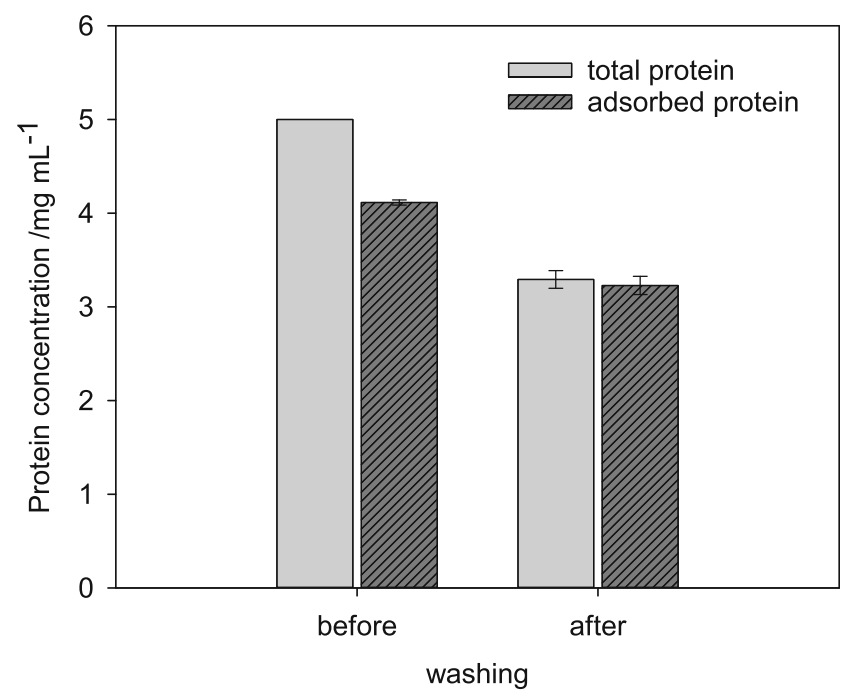

Fig. 2 Total protein concentration and concentration of the adsorbed protein in BS suspensions before and after their washing with buffer protein that is adsorbed on the particles' surface. The proteins do not interact directly with the particles' surface, as do the proteins of the hard corona [22]. Nevertheless, a soft corona reduces the amount of free protein in the continuous phase and increases the hydrodynamic diameter of particles. In our study, BS as well as TS showed increased particle sizes including some large aggregates (Fig. 4). This is in line with the high amounts of protein retained by TS and BS (Fig. 5). We therefore conclude that a soft corona or protein layer had formed around both kinds of SLN. The formation of a soft but not hard corona of BLG around TS similar to those in the present study had been reported before [25]. By contrast, a hard corona of human serum proteins was detected on polysorbate stabilized SLN by Göppert and Müller. They used human serum proteins and assumed that the protein adsorbed either on the hydrophobic side chains of the polysorbate or directly onto the particles surface [18]. Different outcomes of the studies may be attributable to the different proteins and experimental conditions.

The increase in size of TS after protein addition could also have occurred because of SLN aggregation due to protein bridging. In protein enriched TS-suspensions, high amounts

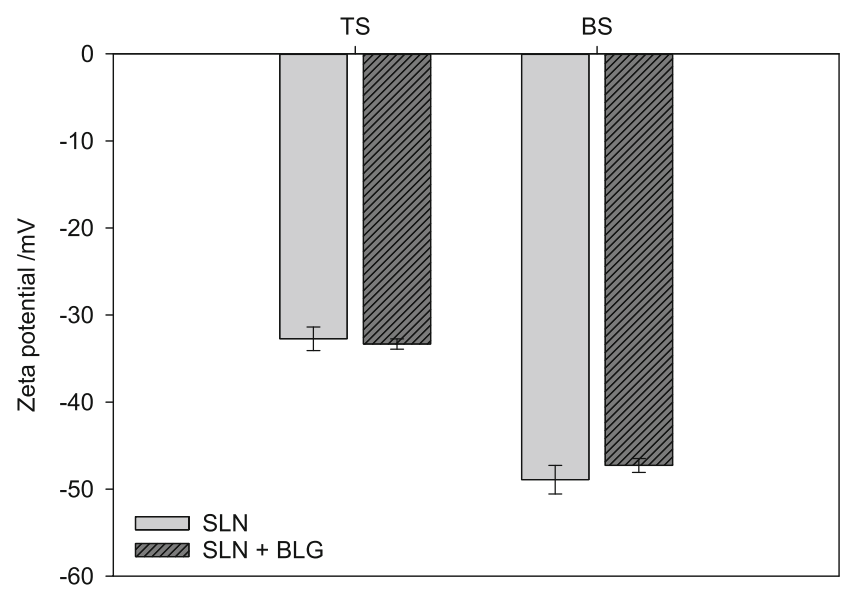

Fig. 3 Zeta potential of SLN before and after an enrichment to $56 \mathrm{mg} / \mathrm{mL}$ protein. SLN were stabilized by Tween 20 (TS) or by $\beta$-lactoglobulin (BS) 
Fig. 4 Cumulative intensity based particle size distributions of SLN stabilized by $\beta$ lactoglobulin (BS) or by Tween 20 (TS). SLN were enriched in bulk phase protein and diluted with buffer or $56 \mathrm{mg} / \mathrm{mL} \beta$ lactoglobulin (BLG) solution protein solution prior to size measurements

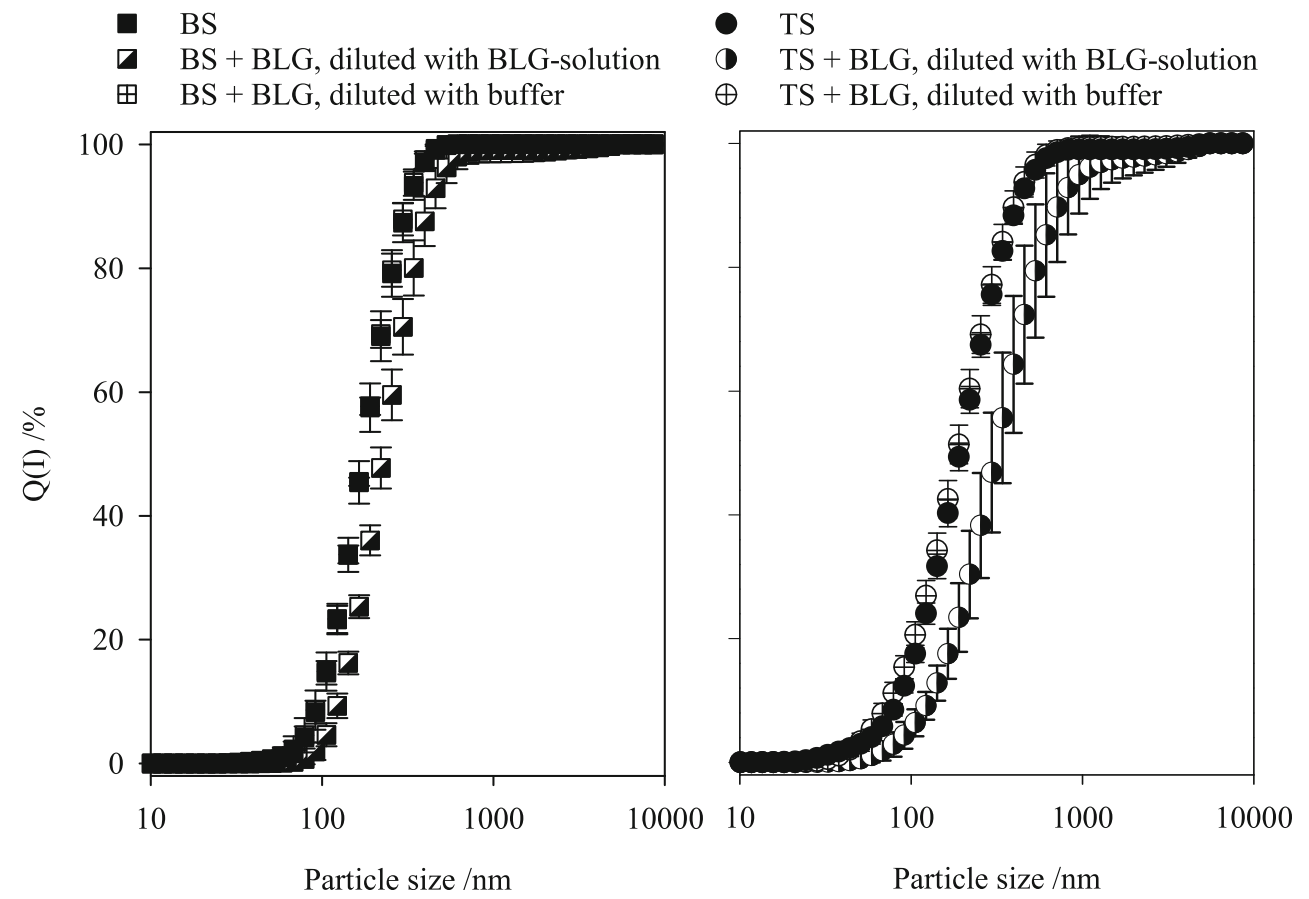

of emulsifier and protein were present and the $\mathrm{pH}$ value was 7 . However, it has been reported, that WPI or BLG stabilized emulsions are stable at $\mathrm{pH}$ values that are far from the isoelectric point ( $\mathrm{pH} 5$ ) and at high protein contents [31,32]. This is probably why only a small extend of coarse fraction was observed.

Concluding, we found that both types of SLN retained protein, probably by the formation of a soft corona. The stabilization of SLN by Tween 20 prevented the formation of a hard corona, but a soft corona had nevertheless been formed.

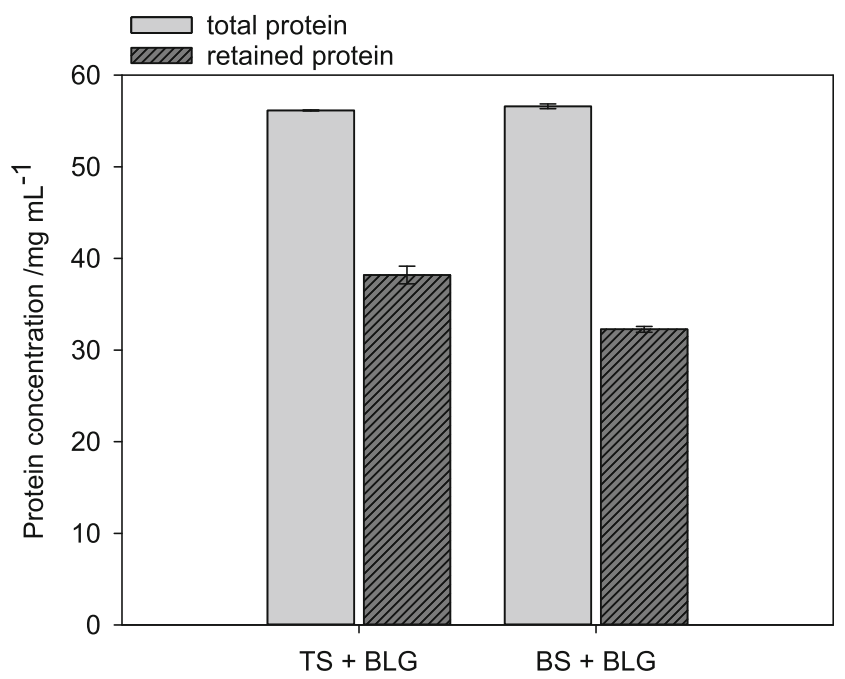

Fig. 5 Total protein concentration and amount of protein retained by protein enriched SLN after ultrafiltration. The amounts were determined for different kinds of SLN: SLN that were stabilized by Tween 20 (TS) and SLN that were stabilized by $\beta$-lactoglobulin (BS)

\section{Heat Stability of SLN in the Absence of Excess Protein}

In our previous study, heat treatment at $90^{\circ} \mathrm{C}$ in the presence of excess protein resulted in an increased size of TS but not of BS [4]. The last part of this paper investigates whether the difference in heat stability was inherent to the two types of SLN or related to the excess protein. We therefore, studied the heat stability of SLN in the absence and presence of excess protein. Subsequently in chapter 3.4, we will compare these results with the heat stability of SLN in the presence of excess protein to distinguish between protein-provoked effects and effects caused by SLN themselves. A good heat stability of SLN independent of possibly present high amounts of protein would be advantageous for the later use in food products.

The heat stability of SLN was studied by heating BS and TS several times at $90{ }^{\circ} \mathrm{C}$ to emphasize and enhance possible changes during heating. Two variants of BS were heat treated: Initial BS that contained a total protein content of $5 \mathrm{mg} / \mathrm{mL}$, and washed BS in which free protein had been removed from the continuous phase (total protein content of $3.3 \mathrm{mg} / \mathrm{mL}$ ). Both kinds of BS were stable against heat induced changes in particle size (Fig. 6). As reflected by the TEM images, no coalescence or aggregation had occurred and BS were still spherical or platelet shaped (Fig. 6c). Similarly, emulsions that were stabilized by WPI or BLG at neutral $\mathrm{pH}$ and low ionic strength have been reported to be stable during heat treatment [33]. Protein that is adsorbed to hydrophobic interphases changes its conformation and its surface hydrophobicity: The hydrophobic regions of the adsorbed protein direct towards the hydrophobic phases (i.e. SLN surface), the polar 
amino acid chains remain in the aqueous phase. Consequently, the surface hydrophobicity of the adsorbed molecules decreases compared to the denatured molecules in the water phase [34]: This phenomenon limits the sites on the particle surface or protein that can interact with denatured protein during and after heating and enhances particle stability during heating which can be determined as constant particle size upon heating.

In contrast, the size of TS increased after each heating cycle (Fig. 6). Except the last one, each heating cycle resulted in a significant increase in particle size compared to the preceding stage. After the first heating cycle, SLN had increased 1.6 fold in size, and after the last one, the particles had a size of over $600 \mathrm{~nm}$. However, TS still had a platelet-like shape after a total heating of $3 \mathrm{~h}$ (Fig. 6b). This indicates that the fat crystals still returned to $\beta$ '-modification after cooling [29]. No signs of aggregation were observed. During the heat treatment, SLN were subjected to a temperature of $90^{\circ} \mathrm{C}$. The melting point of TS was around $45^{\circ} \mathrm{C}$ [2]. I. e. TS were liquid during the heat treatment and destabilization mechanisms like coalescence or aggregation could have occurred. Heat-induced coalescence of droplets in Tween 20 stabilized nano-emulsions was reported by Teo et al., 2016 [35]. They explained the destabilization by a phase separation at temperatures close to the cloud point of the emulsifier. For Tween 20, cloud points between 75 to $80^{\circ} \mathrm{C}$ have been reported [36, 37]. The emulsifier is not anymore able to stabilize droplets above its cloud point and emulsion instabilities can arise. In this study, temperatures above the cloud point of Tween 20 were applied. We therefore suggest that the phase separation of Tween 20 was the reason for the increased particle size of TS after heating.

In summary, we conclude that the hard corona protected BS from coalescence during the heat treatment, whereas TS were not stable against heat induced coalescence. They coalesced probably due to a phase separation between emulsifier and SLN caused by approaching the temperature of the cloud point of Tween 20 during the heat treatment.

\section{Heat Stability of SLN in the Absence and Presence of Excess Protein}

After presenting the stability of SLN upon heat treatment without added protein, we will now discuss the heat stability of protein enriched SLN and compare it with the previous results. Figure 7 presents the size distributions of BS and TS before and after a heat treatment in the absence or in the presence of $56 \mathrm{mg} / \mathrm{mL}$ BLG. BS did not increase in size and were stable during the heat treatment both in the absence and in the presence of excess protein (Fig. 7). This seems to be in contradiction to findings by Euston et al. [42] and Sliwinski et al. [5] who found an increase in droplet size of protein stabilized emulsions when excess protein was present during heating.. They concluded that free protein acted as "glue" that led to the agglomeration of the droplets. However, studies differed in protein concentrations, dispersed phase volume fraction and salt conent. Furthermore, only $2.5 \%$ of dispersed lipid was present in the SLN suspensions compared to $20 \%$ soy oil that was used by Euston et al.. Thus, there was a lower probability of collision of the droplets. Furthermore, Euston used whey protein concentrate that contained typically minerals. Salts are known to reduce the electrostatic stabilization of protein leading to increased aggregation rates of protein [38]. This could be the reason, why they found droplet aggregation whereas we could not find agglomerated BS even if high amounts of non-adsorbed protein were present.

TS, on the other hand, increased in size when protein was absent or present (Fig. 7). TS were stabilized by Tween 20, not by the protein. Nevertheless, the protein formed a cloudy layer around the particles. However, this layer did not stabilize the SLN during the heat treatment, but caused an even more
Fig. 6 a Size of different kinds of SLN after heat treatment: SLN, stabilized by Tween 20 (TS) or $\beta$ lactoglobulin (BS), and BS, containing non-adsorbed protein as well as BS of which the nonadsorbed protein had been removed before heating. Each heating cycle consisted of $30 \mathrm{~min}$ at $90^{\circ} \mathrm{C}$. TEM images show TS after the last heating step (b) and BS after the last heating step (c)

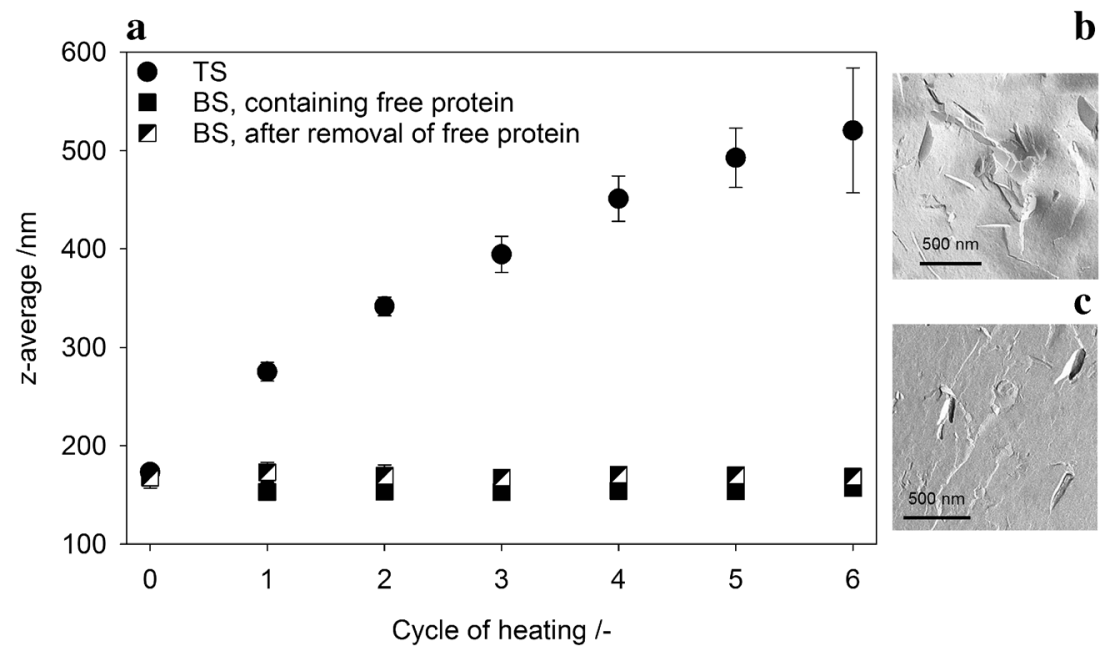


Fig. 7 Cumulative intensity based particle size distributions of different kinds of SLN before and after heat treatment at $90{ }^{\circ} \mathrm{C}$ for $30 \mathrm{~min}$ in the absence and presence of $56 \mathrm{mg} / \mathrm{mL} \beta$-lactoglobulin. SLN were stabilized by Tween 20 (TS) or by $\beta$ lactoglobulin (BS). All samples were diluted by buffer prior to the measurements

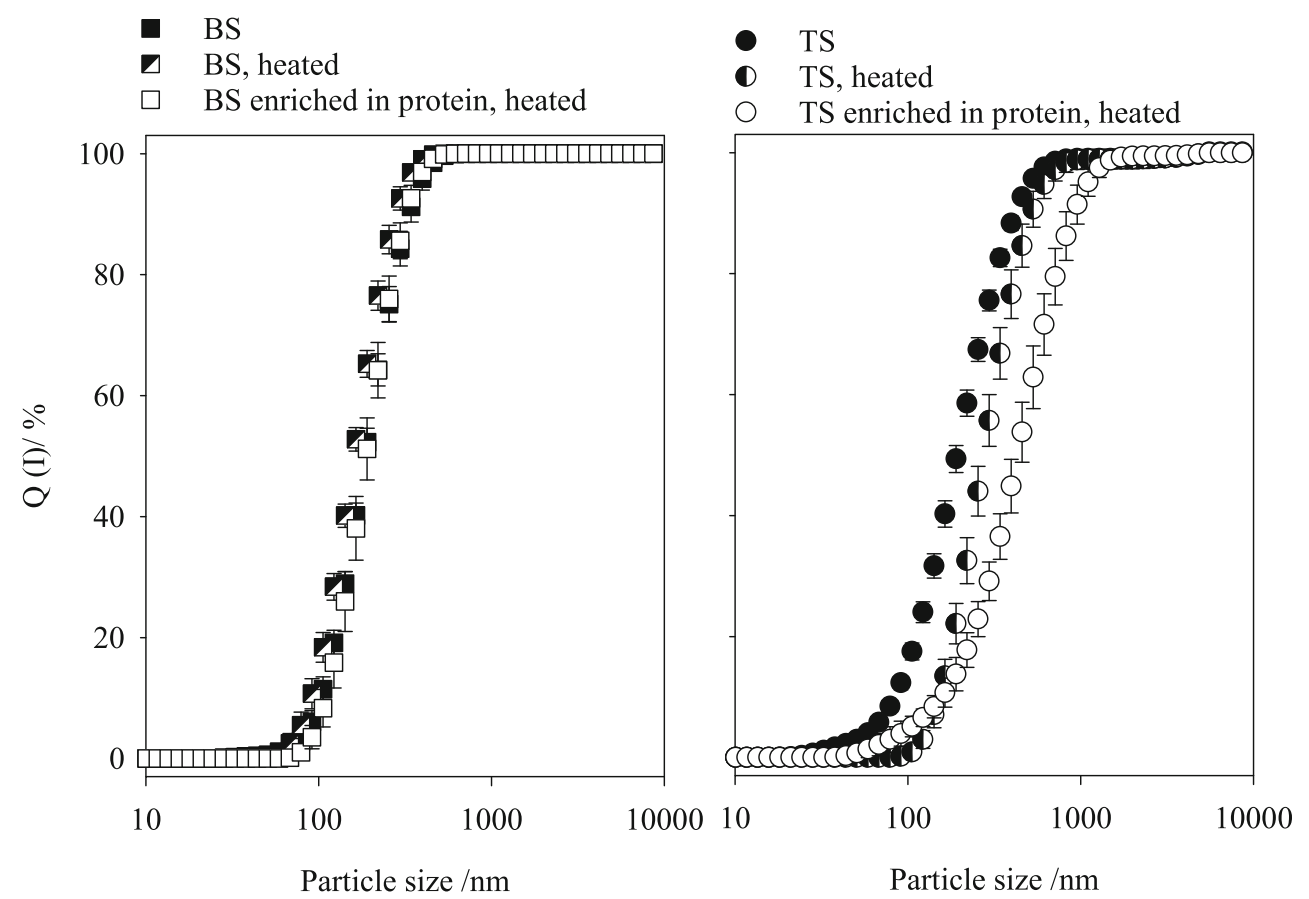

pronounced increase in size compared to protein-free TS suspensions. To our knowledge, the heat or storage stability of Tween stabilized emulsions in the presence of protein has not been reported in the literature. Instead, studies on the stabilities of protein stabilized emulsions in the presence of Tween 20 exist. E.g. Kerstens et al. observed a transformation of a protein stabilized emulsion to a surfactant stabilized emulsion accompanied by coalescence and a clear separation of proteinrich areas and droplet-rich areas during heat treatment [39]. Hence, the initially protein stabilized emulsion was not heat stable in the presence of Tween 20 [39]. We therefore conclude that the Tween 20 present in the TS hindered the protein from stabilizing the nanoparticles by a similar mechanism

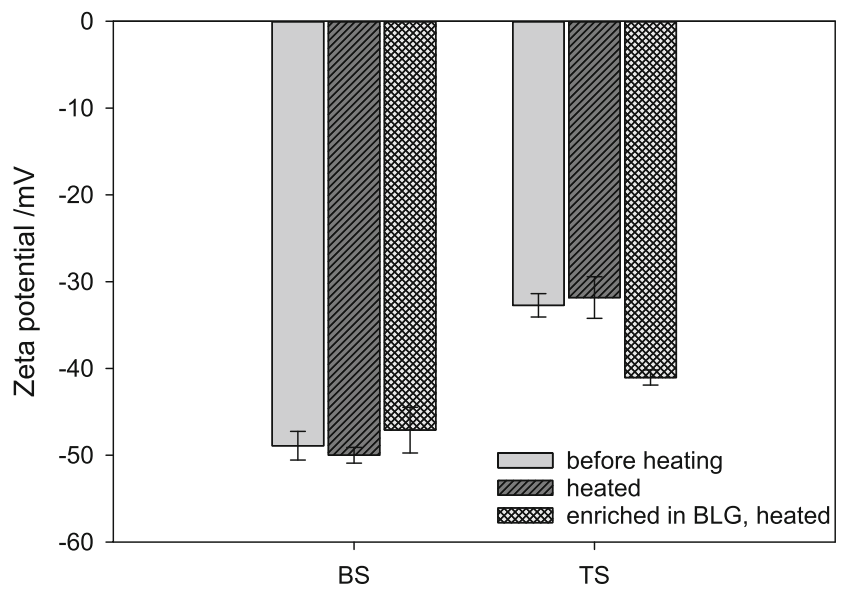

Fig. 8 Zeta potentials of $\beta$-lactoglobulin-stabilized SLN (BS) or Tween 20 -stabilized SLN (TS). Zeta potentials were determined either directly after the production, after a heat treatment in the absence of excess protein or after a heat treatment in the presence of $56 \mathrm{mg} / \mathrm{mL} \beta$-lactoglobulin which resulted in coalescence due to heat induced phase separation.

Other publications found increased heat stabilities of proteinstabilized emulsions if Tween was added [40-42] which seems to be in contrast to the present study. However, compared to our study, the previous reports are based on systems with higher oil contents, larger oil droplets, different proteins (yolk protein and WPC) and shorter heating times (up to $10 \mathrm{~min}$ ). Additionally, phase separation was not described in those studies. Hence, due to the manyfold differences of the studied systems, a final explanation for our observations could not be found and further work has to be done to elucidate the underlying mechanisms.

The zeta potential of SLN heated in the absence and presence of BLG is shown in Fig. 8. The zeta potential of BS either enriched in protein or not did not change after heat treatment. TS also exhibited the same zeta potential before and after heat treatment in the absence of protein. In contrast, if TS were enriched in protein and heated, the absolute value of the zeta potential increased from approximately $32 \mathrm{mV}$ to about $41 \mathrm{mV}$. This could have been due to an adsorption of some protein molecules on the surface after the heat treatment. The adsorption of BLG could have also led to the more pronounced increase in size that was oberserved after the heating of TS in the presence of BLG (Fig. 7).

\section{Conclusion}

In this paper, the stability of SLN was examined as a function of presence/ absence of excess protein, heating, and emulsifier used for SLN stabilization. SLN were stabilized by two 
different emulsifiers, namely Tween 20 (TS) and BLG (BS). The SLN suspensions were characterized before and after a heat treatment and were heated in the absence and presence of excess protein. The characterization included the particle size as well as the zeta potential.

BS exhibited an adsorption layer of protein (hard corona). Furthermore, a soft corona developed if the BS suspension was enriched in protein. No adsorption layer (hard corona) occurred around TS. However, a cloudy layer (soft corona) formed around the SLN if the suspensions were enriched in protein.

We were able to demonstrate that SLN can be heated in the presence and absence of protein without a break down of the emulsion. We could further experimentally prove that the adsorption layer of protein formed at room temperature does not necessarily influence the stability of SLN during heat treatment. In fact, BS were stable even in the presence of high amounts of free protein. TS were not stable during heating and the cloudy protein layer around TS was not able to stabilize them against coalescence. The increase in size was even more pronounced when protein was present, possibly due to protein-adsorption onto their surface as revealed by the altered zeta potential.

We could hence show that the choice of emulsifier used to stabilize the SLN influenced the heat stability of SLN. This has implications for the use of SLN as encapsulation systems in food products. By a proper choice of emulsifiers, properties of SLNbased encapsulation systems can be modulated in a targeted way. However, the behavior of TS during the heat treatment in presence or in absence of protein could not be clarified in detail. Further work is necessary to study the interactions between TS and protein at temperatures above the cloud and melting point of Tween 20 and tristearin, respectively.

Acknowledgments The authors thank Karin Heck, Michael Wörner and Ramona Ring for their excellent technical assistance and help. This work was supported by funds of the Federal Ministry of Food and Agriculture (BMEL) based on a decision of the Parliament of the Federal Republic of Germany via the Federal Office for Agriculture and Food (BLE) under the innovation support program.

\section{Compliance with Ethical Standards}

Conflict of Interest The authors declare no conflict of interest.

Open Access This article is distributed under the terms of the Creative Commons Attribution 4.0 International License (http:// creativecommons.org/licenses/by/4.0/), which permits unrestricted use, distribution, and reproduction in any medium, provided you give appropriate credit to the original author(s) and the source, provide a link to the Creative Commons license, and indicate if changes were made.

\section{References}

1. U.S. Schmidt, R. Bernewitz, G. Guthausen, H.P. Schuchmann, Colloids Surf. A Physicochem. Eng. Asp. 475, 55-61 (2015)
2. K. Oehlke, D. Behsnilian, E. Mayer-Miebach, P.G. Weidler, R. Greiner, PLoS One 12(2), e0171662 (2017)

3. D.J. McClements, Adv. Colloid Interf. Sci. 219, 27-53 (2015)

4. V. Wiedenmann, K. Oehlke, U. van der Schaaf, B. Hetzer, R. Greiner, H.P. Karbstein, Food Hydrocoll. 84, 498-507 (2018)

5. E.L. Sliwinski, P.J. Roubos, F.D. Zoet, M.A.J.S. van Boekel, J.T.M. Wouters, Colloids Surf. B: Biointerfaces 31(1), 231-242 (2003)

6. S.R. Euston, S.R. Finnigan, R.L. Hirst, Food Hydrocoll. 14(2), 155-161 (2000)

7. H.J. Kim, E.A. Decker, D.J. McClements, Langmuir 21(1), 134139 (2005)

8. R. Gref, M. Lück, P. Quellec, M. Marchand, E. Dellacherie, S. Harnisch, T. Blunk, R.H. Müller, Colloids Surf. B: Biointerfaces 18(3), 301-313 (2000)

9. Y. Zhang, N. Kohler, M. Zhang, Biomaterials 23(7), 1553-1561 (2002)

10. S.M. Moghimi, J. Szebeni, Prog. Lipid Res. 42(6), 463-478 (2003)

11. P.d. Pino, B. Pelaz, Q. Zhang, P. Maffre, G.U. Nienhaus, W.J. Parak, Materials Horizons 1(3), 301-313 (2014)

12. T. Cedervall, I. Lynch, S. Lindman, T. Berggard, E. Thulin, H. Nilsson, K.A. Dawson, S. Linse, Proc. Natl. Acad. Sci. 104(7), 2050-2055 (2007)

13. D. Hühn, K. Kantner, C. Geidel, S. Brandholt, I. de Cock, S.J.H. Soenen, P. Rivera_Gil, J.M. Montenegro, K. Braeckmans, K. Müllen, G.U. Nienhaus, M. Klapper, W.J. Parak, ACS Nano 7(4), 3253-3263 (2013)

14. R. Huang, R.P. Carney, F. Stellacci, B.L.T. Lau, Nanoscale 5(15), 6928-6935 (2013)

15. M. Lundqvist, J. Stigler, G. Elia, I. Lynch, T. Cedervall, K.A. Dawson, Proc. Natl. Acad. Sci. 105(38), 14265-14270 (2008)

16. J.S. Gebauer, M. Malissek, S. Simon, S.K. Knauer, M. Maskos, R.H. Stauber, W. Peukert, L. Treuel, Langmuir 28(25), 96739679 (2012)

17. T. M. Göppert and R. H. Müller, Int. J. Pharm. 302 (1-2), 172-186 (2005), 172

18. T.M. Göppert, R.H. Müller, J. Drug Target. 13(3), 179-187 (2005)

19. E. Casals, T. Pfaller, A. Duschl, G.J. Oostingh, V. Puntes, ACS Nano 4(7), 3623-3632 (2010)

20. M. Mahmoudi, A.M. Abdelmonem, S. Behzadi, J.H. Clement, S. Dutz, M.R. Ejtehadi, R. Hartmann, K. Kantner, U. Linne, P. Maffre, S. Metzler, M.K. Moghadam, C. Pfeiffer, M. Rezaei, P. RuizLozano, V. Serpooshan, M.A. Shokrgozar, G.U. Nienhaus, W.J. Parak, ACS Nano 7(8), 6555-6562 (2013)

21. S. Tenzer, D. Docter, S. Rosfa, A. Wlodarski, J. Kuharev, A. Rekik, S.K. Knauer, C. Bantz, T. Nawroth, C. Bier, J. Sirirattanapan, W. Mann, L. Treuel, R. Zellner, M. Maskos, H. Schild, R.H. Stauber, ACS Nano 5(9), 7155-7167 (2011)

22. S. Milani, F. Baldelli Bombelli, A.S. Pitek, K.A. Dawson, J. Rädler, ACS Nano 6(3), 2532-2541 (2012)

23. J. Yang, B. Wang, Y. You, W.J. Chang, K. Tang, Y.C. Wang, W. Zhang, F. Ding, S. Gunasekaran, Nanoscale 9(45), 17758-17769 (2017)

24. T. Winuprasith, M. Suphantharika, D. J. McClements and L. He, J. Colloid Interface Sci. 416 (0), 184-189 (2014)

25. K. Oehlke, J.K. Keppler, J. Milsmann, E. Mayer-Miebach, R. Greiner, A. Steffen-Heins, J. Food Eng. 247, 144-151 (2019)

26. J.K. Keppler, F.D. Sönnichsen, P.-C. Lorenzen, K. Schwarz, Biochimica et Biophysica Acta (BBA)- Proteins and Proteomics 1844(6), 1083-1093 (2014)

27. K. Schrader, W. Buchheim and C. V. Morr, 41 (3), 133-138 (1997)

28. T. Harnsilawat, R. Pongsawatmanit, D.J. McClements, Food Hydrocoll. 20(5), 577-585 (2006)

29. H. Bunjes, F. Steiniger, W. Richter, Langmuir 23(7), 4005-4011 (2007)

30. J. Chen, E. Dickinson, J. Sci. Food Agric. 62(3), 283-289 (1993) 
31. K. Demetriades, J.N. Coupland, D.J. McClements, J. Food Sci. 62(2), 342-347 (1997)

32. H.J. Kim, E.A. Decker, D.J. McClements, Langmuir 18(20), 7577 7583 (2002)

33. E. Dickinson, Colloids Surf. B: Biointerfaces 81(1), 130-140 (2010)

34. K.P. Das, J.E. Kinsella, J. Colloid Interface Sci. 139(2), 551-560 (1990)

35. A. Teo, K.K.T. Goh, J. Wen, I. Oey, S. Ko, H.S. Kwak, S.J. Lee, Food Chem. 197 (Part A(Pt A), 297-306 (2016)

36. J. Chawla, R.K. Mahajan, J. Dispers. Sci. Technol. 32(6), 822-827 (2011)
37. M. KGaA, Merck KGaA (Darmstadt, Germany, 2018)

38. J.A. Hunt, D.G. Dalgleish, J. Food Sci. 60(5), 1120-1123 (1995)

39. S. Kerstens, B.S. Murray, E. Dickinson, J. Colloid Interface Sci. 296(1), 332-341 (2006)

40. C.V. Nikiforidis, V. Kiosseoglou, Food Hydrocoll. 21(8), 1310 1318 (2007)

41. Y. Liang, H. Patel, L. Matia-Merino, A. Ye, M. Golding, Food Hydrocoll. 33(2), 297-308 (2013)

42. S.R. Euston, S.R. Finnigan, R.L. Hirst, Food Hydrocoll. 15(3), 253-262 (2001)

Publisher's Note Springer Nature remains neutral with regard to jurisdictional claims in published maps and institutional affiliations. 